\title{
Literatura queer e latina nos Estados Unidos: interseccionalidades entre etnia, gênero e sexualidade em dois contos
}

\section{Queer and latino literature in the United States: intersectionalities between ethnicity, gender and sexuality in two short stories}

\author{
William Duarte Ferreira* \\ willduarte12@gmail.com \\ Universidade Federal da Integração Latino-Americana (UNILA) \\ Mirian Santos Ribeiro de Oliveira** \\ mirian.oliveira@unila.edu.br \\ Universidade Federal da Integração Latino-Americana (UNILA)
}

RESUMO: Este artigo tem como objetivo analisar de que maneira se dá a construção de personagens queer na literatura quando constituídos de maneira interseccional à identidade latina nos Estados Unidos. Para isso, foram selecionados dois contos da coletânea From macho to mariposa: new gay latino fiction (2011), organizada por Charles Rice-González e Charlie Vázquez. Verificou-se, assim, de que maneira a interseccionalidade étnica que compõe a identidade desses sujeitos, a saber, a ascendência latino-americana, afeta suas vivências enquanto sujeitos queer, além de discutir o modo pelo qual esses sujeitos, já segregados devido a questões étnicas e culturais, sofrem um novo processo de marginalização em função de sua expressão de gênero e/ou sexualidade.

PALAVRAS-CHAVE: Identidade. Teoria queer. Latinos. Interseccionalidade.

ABSTRACT: This paper aims to analyze the way in which queer characters are developed when they are constructed in an intersectional way with the Latino identity in the United States. In order to do that, we selected two short stories from the collection From macho to mariposa: new gay latino fiction (2011), edited by Charles Rice-González and Charlie Vázquez, in which we investigated how the ethnical intersectionality that forms the identity of the individuals in those stories - the LatinAmerican ascendency - affect their lives as queer. In addition to that, we also discuss how those characters, who have been already segregated due to ethnical and cultural differences, are once more marginalized on account of their gender expression and/or their sexuality.

KEYWORDS: Identity. Queer theory. Latinos. Intersectionality.

\footnotetext{
* Mestrando em Literatura Comparada pela Universidade Federal da Integração Latino-Americana (UNILA). Bolsista CAPES.

** Doutora em Sociologia pela Universidade de São Paulo (USP). Atua como professora Adjunta da Universidade Federal da Integração Latino-Americana (UNILA).
} 


\section{Introdução}

Hall (2006) defende que as sociedades modernas - e, consequentemente, os sujeitos que as compõem - estão sendo "descentradas", ou seja, deslocadas ou fragmentadas, e atribui isso aos processos de globalização. Essa ideia, naturalmente, opõe-se aos discursos da cultura nacionalista que reverberam uma noção de unidade e coerência interna, ignorando, assim, o quão diferentes seus membros possam ser em termos de classe, gênero e etnia. $O$ que ocorre, explica o teórico, é que, apesar das divisões e diferenças internas existentes nessas sociedades, é gerada uma "unificação" por meio de um dispositivo discursivo operado a partir da ação de diferentes formas de poder cultural.

Os Estados Unidos, por exemplo, estabelecem noções culturais que se voltam quase que exclusivamente à cultura WASP (White, Anglo-Saxon and Protestant ${ }^{1}$ ) ignorando, assim, a heterogeneidade que compõe seu território. Dentre essa diversidade étnica, o presente artigo evidencia os chamados "latinos", termo utilizado para se referir aos indivíduos nascidos e/ou criados nos Estados Unidos de ascendência latino-americana.

Este artigo, no entanto, não se volta de maneira exclusiva à cultura latina nos Estados Unidos; o que busca é, na verdade, compreender como se dá a construção dos sujeitos queer - por meio do texto literário - quando constituídos de maneira inteseccional à identidade latina, ou seja, a partir do diálogo entre elementos étnicos, de gênero e sexualidade. Para isso, foram selecionados, como corpus de análise, dois contos presentes na coletânea From macho to mariposa: new gay latino fiction (2011), organizada por Charles Rice-González e Charlie Vázquez.

Assim, diante do exposto, este estudo visa responder às seguintes questões de pesquisa:

Como se dá a construção dos sujeitos queer na literatura produzida por latinos nos Estados Unidos?

$>$ De que maneira os elementos identitários relativos à cultura latina agem como dispositivos de controle em favor da normatização dos sujeitos queer?

Para que seja possível atingir os objetivos aqui propostos, é adotada uma perspectiva de pesquisa comparativista. Sobre isso, é relevante a menção de que

${ }^{1}$ Branca, Anglo-Saxã e Protestante. 
não há, conforme esclarecem Machado e Pageaux (1998), um método comparativista, mas questões a serem sanadas por meio das relações existentes entre literaturas, fenômenos culturais, autores, etc. Essa investigação, naturalmente, ocorre de maneira interdisciplinar e de acordo com os métodos de abordagem dos fatos e textos literários, segundo a natureza da problemática levantada.

O artigo, então, está organizado da seguinte forma: na primeira parte, são discutidas questões relacionais à identidade latina nos Estados Unidos e algumas características de sua produção literária. Na segunda parte, são apresentados, brevemente, elementos que constituem os estudos queer para que, a partir disso, seja possível refletir acerca da maneira pela qual os elementos da cultura latina afetam a vivência dos sujeitos queer nos contos analisados. Para além disso, não obstante o fato de os sujeitos aqui analisados se constituírem enquanto seres ficcionais, são abordadas questões teóricas a respeito da personagem de fiç̧ão. Finalmente, na terceira parte, os contos selecionados como corpus deste estudo, a saber, "Huerfanita" (2011), de David Andrew Talamentes, e "On the line" (2011), de Benny Vásquez, são analisados a fim de que seja possível compreender como se dá a construção dos sujeitos queer e de que maneira os elementos relacionados à cultura latina agem como agentes disciplinadores em favor das normas de gênero e sexualidade.

\section{Identidades e literaturas latinas nos Estados Unidos}

O final do século XX testemunhou, de acordo com Torres (2001), uma crescente "latinização" dos Estados Unidos. Esse fenômeno, no entanto, não parece estar associado a uma maior incorporação da cultura latina ao espaço hegemônico anglo-saxão ou, ainda, sua aceitação pela cultura dominante. A diáspora latinoamericana nos Estados Unidos, portanto, mesmo que se configure como a maior minoria étnica do país, segue ocupando um espaço marginalizado. É curioso perceber, nesse contexto, como muitos desses indivíduos são oprimidos em favor da cultura hegemônica com a qual se relacionam em um território que antes thes pertencia - como é o caso dos chicanos ou mexicanos-americanos - uma vez que o que hoje é o sudoeste dos Estados Unidos foi, inicialmente, colonizado por espanhóis, tornando-se território do México após sua independência; apenas após a 
guerra entre Estados Unidos e México e com a assinatura do Tratado de GuadalupeHidalgo é que esse território se tornou estadunidense (TORRES, 2001).

Nesse contexto, ainda que constantemente oprimidos em um meio que lhes é hostil, os chamados "latinos" não apenas se hibridizam por meio de um processo dialógico entre culturas, como também ressignificam os espaços que ocupam, conforme explica López (2015). Contribuem, inclusive, para o desenvolvimento de novas expressões estéticas, a exemplo das chamadas literatura chicana e literatura niuyorriqueña, responsáveis por refratar as tensões sociais e culturais que permeiam as relações entre as culturas mexicanas e porto-riquenhas, respectivamente, e a cultura anglo-saxã norte-americana. É, portanto, essa subdivisão de grupos étnicos - chicanos, niyorriqueños, cubanos-americanos, dentre outros - que evidencia o fato de o rótulo étnico "latino" ser nada mais que um termo guarda-chuva para identidades culturais heterogêneas e complexas e que, muitas vezes, percorrem trajetórias e habitam territórios distintos (TORRES, 2011; LÓPEZ, 2014).

Evidentemente, não é possível discutir tais literaturas sem levarmos em consideração o impacto que estas causam. É inegável, por exemplo, que o desenvolvimento da produção literária latina nos Estados Unidos culminou em um processo de redefinição do que vem a ser a literatura norte-americana ao mesmo tempo em que problematiza e expande os elementos geopolíticos e culturais daquilo que denominamos de literatura latino-americana (LÓPEZ, 2004, 2014). Nessa perspectiva, é importante ressaltar, ainda, que as literaturas produzidas por subgrupos étnicos cruzam constantemente as fronteiras disciplinares, uma vez que sobrepõem o cultural e o histórico ao literário.

Dentre os elementos constitutivos dessas literaturas, é, talvez, a construção linguística sua característica mais marcante, posto que são obras marcadas pela utilização do inglês, espanhol e as mais diversas combinações entre as duas línguas - dentre as quais é possível destacar o Spanglish e codeswitching (ou alternância de código). Esse elemento, na verdade, refrata a realidade linguística do cotidiano dos sujeitos latinos que, assim como suas identidades, também são possuidores de uma língua que é hibrida. Além disso, Torres (2001) evidencia como essa hibridez linguística desafia o projeto cultural nacionalista estadunidense, voltado de maneira particular à cultura WASP. 


\section{O queer, o latino e o ficcional: diálogos possíveis}

O termo queer, originalmente, corresponde ao "estranho", "excêntrico", e, em países de língua inglesa, foi utilizado para se referir - de maneira pejorativa - aos sujeitos homoeróticos"; em português, seria equivalente a "bicha", "viado", dentre outros (FERNANDES, 2012). O termo, portanto, nos remete ao contexto de violência e discriminação enfrentado por aqueles sujeitos que se afastam dos padrões heteronormativos vigentes, de modo que, ao adotá-lo, os sujeitos queer subvertem tais sentidos a partir de uma conjuntura política que luta pela quebra dessa normatização.

Queer é, então, conforme explica Louro (2009), muito mais que um termo genérico para gays, lésbicas, bissexuais, e transgêneros de todas as colorações. Tendo ganhado força política e teórica, é uma maneira de designar um modo transgressivo de estar e de pensar no mundo: "supõe a não-acomodação, admite a ambiguidade, o não-lugar, o trânsito, o estar-entre. Sugere fraturas na episteme dominante" (LOURO, 2009, p. 135). É se apoiando nessa diversidade de sentidos inerentes ao termo que Córdoba (2007, p. 23) afirma que desenvolver pesquisas a partir da epistemologia dos estudos queer é, antes de mais nada, um ato de provocação e reinvindicação política:

Construir un discurso queer implica por lo tanto situarse en un espacio extraño que nos constituye como sujetos extraños de un conocimiento extraño, inapropiado, malsonante. Hacer y hablar de teoria queer es, en este contexto, asumir un cierto acto político de intervención enunciativa por la cual, en un cierto sentido, se suspende la autoridad de la disciplina académica y se la increpa desde uno de sus márgenes, con el objetivo de movilizar y desplazar ese margen. ${ }^{3}$

2 O termo "homoerotismo" tem sido frequentemente utilizado em detrimento do termo "homossexualidade" uma vez que extingue a carga semântica patológica implícita neste. Parece, portanto, descrever de maneira mais eficiente a pluralidade de práticas e desejos entre pessoas do mesmo sexto (FERNANDES, 2012). Utilizaremos o termo de acordo com as possibilidades interpretativas dos textos literários em questão sem, no entanto, aplicá-lo de maneira generalizada já que as temáticas abordadas nos contos nem sempre trazem à tona a questão homoerótica, conforme explicitam as análises realizadas.

${ }^{3}$ Nossa tradução: "Construir um discurso queer implica situar-se em um espaço estranho, que nos constitui como sujeitos estranhos, detentores de um conhecimento estranho, inapropriado, inconveniente. Fazer e falar sobre teoria queer é, neste contexto, assumir determinada posição política de intervenção enunciativa em que a autoridade e a disciplina acadêmica são suspensas e repreendidas a partir de um local marginalizado, com o objetivo de mobilizar e deslocar essa margem". 
Esse aspecto é particularmente relevante aqui uma vez que, nos contos analisados, deparamo-nos com sujeitos que se encontram em processos de constante marginalização: seja pela sua condição queer, seja por fazerem parte de minorias étnicas ou, ainda, por se assumirem como sujeitos queer em uma comunidade que, apoiando-se em elementos sociais, culturais e religiosos, rejeita a prática homoerótica ou qualquer elemento que possa remeter a ela. Sobre este último aspecto, é possível citar como exemplo a construção sociocultural do conceito de masculinidade presente neste contexto, responsável pela noção de que o ser queer vai de encontro ao que é ser latino, tornando o processo de autoaceitação e de afirmação entre esses sujeitos extremamente difícil e dolorosa.

Não podemos perder de vista, também, que os sujeitos queer que nos interessam no momento são construídos em narrativas ficcionais; é pertinente, portanto, elucidar algumas questões em torno da personagem de ficção.

Cândido (2009), partindo da caracterização da personagem como um ser fictício, reflete acerca do paradoxo gerado ante a hipótese de a ficção ser; como é possível, questiona-se o autor, existir o que não existe? Embora paradoxal, é necessário compreender a noção de um ser ficcional capaz de transmitir a mais pura impressão de verdade existencial como algo inerente à criação literária. $O$ que ocorre, conforme explica Brait (1985, p. 71), é que "as personagens representam pessoas, segundo modalidades próprias da ficção": são e estão no texto, seu espaço de existência e, sendo aquilo que há de mais vivo na narrativa e, consequentemente, seu elemento mais atuante e comunicativo, propiciam a identificação intelectual e afetiva do leitor (CÂNDIDO, 2009).

Nesse bojo, é necessária, também, a compreensão de que esses "seres de papel" são essencialmente sociais e historicamente concretos, de modo que suas vozes se constroem como posições axiológicas em relação ao mundo, uma vez que a linguagem construída no texto literário "é sempre um ponto de vista peculiar sobre o mundo, que aspira a uma significação social” (BAKHTIN, 2015, p. 125). A palavra, nesse contexto, adquire um caráter bivocal, em que se encontram sobrepostas duas intenções discursivas: "a intenção direta da personagem falante e a intenção refratada do autor" (BAKHTIN, 2015, p. 113). O autor, portanto, torna-se aquele que organiza as diferentes falas e linguagens da vida literária e extraliterária em sua obra, sem, no entanto, enfraquecer essas vozes e discursos; seu oficio é o exato oposto: fortalecer as falas e linguagem heterodiscursivas alheias que estão 
presentes em sua obra, preservando-as e moldando-as às suas novas intenções (BAKHTIN, 2015). Nessa perspectiva, o texto literário configura-se como uma arena ideológica em que podemos verificar a refração dos embates e as tensões sociais existentes em torno dos temas tratados em seu plano ficcional, revelando, assim, a relevância dos estudos literários não só na área estética, mas também no âmbito cultural e social (FERNANDES, 2012).

Sobre os contos a serem analisados - "Huerfanita (TELAMANTES, 2011) e "On the line" (VÁSQUEZ, 2011) -, ambos fazem parte da coletânea From macho to mariposa: new gay latino fiction (2011). Organizada pelo porto-riquenho Charles Rice-González e pelo americano de ascendência cubana e porto-riquenha Charlie Vázquez, a coletânea surgiu a partir do desejo do primeiro de finalizar o hiato de mais de dez anos desde a publicação das últimas antologias de contos queer escritas por autores latinos nos Estados Unidos, Bésame Mucho: new gay latino fiction e Virgens, Guerrillas and Locas: gay latinos writing about love, ambas de 1999. Assim, em um universo de vinte e nove contos escritos por autores de diferentes ascendências e autodeclarados latinos, foram selecionados dois contos: "Huerfanita" (2011), de David Andrew Telamantes, um "gay fronterizo" nascido e criado em El Paso, Texas - fronteira dos Estados Unidos com o México; e "On the line" (2011), de Benny Vásquez, um "queer latino" nativo do Brooklyn e vice-diretor do Border Crosser, projeto social que visa à busca por igualdade racial. A escolha desses contos se deu justamente pelos diversos elementos análogos na construção dessas narrativas, como será possível perceber nas análises que seguem, especialmente por abordarem sujeitos que, ainda que se encontrem em momentos diferentes de sua vida, precisam se afirmar como indivíduos queer (e latinos).

\section{3 "...how to be un hombre macho": análises}

Os contos aqui analisados abordam e problematizam desde suas primeiras orações a condição queer de suas personagens. Assim, ainda que Pablo, de "Huerfanita" (TALAMENTES, 2011), e Emilio, de "On the line" (VÁSQUEZ, 2011), encontrem-se em momentos distintos de suas vidas - este na adolescência e aquele ainda na infância - é perceptível como a construção desses personagens ocorre de maneira análoga, especialmente no que diz respeito à postura destes diante dos padrões de gênero que Ihes são impostos. Contudo, antes de pormenorizar essa 
construção, faz-se necessário esclarecer os elementos em torno da caracterização de sexo-gênero-sexualidade.

Existe uma noção bastante consagrada, de acordo com Louro (2004), que supõe e institui uma sequência natural em torno de uma lógica binária no que concerne esses três elementos. Logo, o sexo (visualizado, neste caso, como biológico) determina um gênero (dentre apenas dois possíveis) e resulta em uma forma de desejo (sempre dirigida ao sexo oposto). Como, contudo, tal sequência não é segura ou indiscutível - sendo, na verdade, constantemente desafiada e subvertida - são empreendidos vários esforços no sentido de assegurar seu funcionamento e continuidade (LOURO, 2004). Dentre tais esforços, existem processos que buscam definir, por meio de posturas dicotômicas, elementos que constituem o masculino e o feminino, traçando, assim, fronteiras normativas em relação à expressão de gênero e sexualidade dos indivíduos. Essa discussão, portanto, possibilita que enxerguemos, conforme as análises que seguem, que tanto Pablo como Emilio se tornam agentes em favor da quebra dessa sequência institucionalizada, cada qual, naturalmente, a partir do ciclo da vida em que se encontram.

Pablo, por exemplo, quebra com as expectativas desejáveis ao masculino quando escolhe a cor rosa como tema de sua festa de aniversário de sete anos, ignorando, inclusive, a rejeição social que esta escolha lhe acarretaria: "The guests would be mostly family, perhaps a few girls from his class, but none of the boys would be interested" (TALAMENTES, 2011, p. 01, grifo meu) ${ }^{4}$. Essa rejeição, naturalmente, é decorrente das rígidas fronteiras de gênero que, ao estabelecer características e elementos tidos pela tradição como naturalmente masculinos ou femininos, acabam por dicotomizar meninos e meninas de maneira tão acentuada que a (aparentemente) simples escolha de uma cor se torna passível de desestabilizar a ordem lógica normativa socialmente estabelecida.

Existem, ainda, outros elementos relativos à expressão de gênero do garoto que reiteram a quebra com os padrões apontados como masculinos: sua inabilidade na prática de esportes e trabalhos mecânicos, seu gosto por telenovelas, suas

\footnotetext{
${ }^{4}$ Nossa tradução: "Os convidados seriam, basicamente, seus familiares, talvez algumas garotas de sua classe, mas nenhum dos garotos iria se interessar".
} 
preferências musicais e sua habilidade para a dança, coerente com o seu maior desejo: "Pablo wanted to be a Madonna dancer" (TALAMENTES, 2011, p. 3$)^{5}$.

De maneira semelhante, Emílio, em "On the Line" (VÁSQUEZ, 2011), também é responsável por quebrar com a sequência lógica que institui uma continuidade entre sexo, gênero e sexualidade. Essa quebra, contudo, não se limita à expressão de gênero, encontrando-se expressa pelo desejo homoerótico que este nutre por seu amigo, Danny.

- Want me to tell you a fantasy?

- Sure.

- Okay, lie down. Close your eyes and listen to my voice.

I felt my skin tingle, my heart race, and my ears open. As my breath grew heavier, I waited on every word he had to say. Every syllable was like a kiss covering an inch of my body. He continued to tease me with his voice, having me imagine a girl (it was always a girl) kissing the tip of my dick. As the word dick flowed from his mouth, he rubbed his rough and slightly wet fingertip along the outline of my lips. - Do you like it? (VÁSQUEZ, 2011, p. 09) ${ }^{6}$.

O desejo, a partir de seu significado dicionarizado, pode ser classificado como um querer, aspiração ou vontade, expectativa de possuir ou alcançar algo, relacionando-se a algo que nos falta e que buscamos alcançar. Na psicanálise, explica Fernandes (2012), o desejo adquire um caráter quase exclusivamente sexual, sendo "na relação com o outro que o desejo se concretiza, não apenas no desejo pelo outro, mas no desejo de ser para ele objeto de desejo" (FERNANDES, 2012, p. 29). Naturalmente, o desejo não pode ser considerado apenas como a busca pela satisfação sexual, sendo este apenas uma face dele; é possível classificar, então, o desejo "como uma categoria ou conceito incorporado ao existir dos sujeitos, portanto, associado tanto ao corpo como à alma” (FERNANDES, 2012, p. 29).

Nessa perspectiva, podemos visualizar no excerto apresentado a manifestação do desejo entre Emilio, narrador do conto, e Danny. É possível perceber, no entanto, que há uma tentativa de reprimir o teor homoerótico ali existente por meio da imagem feminina: "it was always a girl” (VÁSQUEZ, 2011, p.

\footnotetext{
${ }^{5}$ Nossa tradução: "Pablo sonhava em ser um dançarino da Madonna".

${ }^{6}$ Nossa tradução: "- Quer ouvir uma fantasia? / - Claro. / - Tudo bem, deite-se. Feche os olhos e escute minha voz. / Minha pele se arrepia, meu coração acelera e meus ouvidos escutam atentamente. Enquanto minha respiração se intensifica, entrego-me a cada palavra que ele tem a dizer. Suas sílabas eram como beijos cobrindo cada centímetro do meu corpo. Ele continua a me excitar com a sua voz, fazendo-me imaginar uma garota (era sempre uma garota) beijando a cabeça do meu pau. Enquanto a palavra "pau" brotava de sua boca, ele roçava a ponta do seu dedo pelo contorno dos meus lábios. / - Você gosta?"
} 
09) ${ }^{7}$. Não obstante, é evidente que o desejo de Emilio se volta ao amigo. É perceptível como o corpo daquele se manifesta desde as primeiras palavras deste; sua pele, seu coração e sua respiração reagem à voz do outro e, para além disso, o fato de o amigo incitá-lo a fantasiar com o sexo oposto parece gerar descontentamento neste.

Embora o jogo de fantasias entre os amigos seja constante, nenhum exterioriza o desejo que parecem nutrir pelo outro. Danny, inclusive, sempre se utiliza de artifícios para mascará-lo. Tal postura, evidentemente, não é estranha, mesmo aos "personagens da vida real" quando percebem que seu desejo está direcionado a uma pessoa do mesmo sexo. Conforme discutido anteriormente, uma série de práticas foram instauradas na intenção de assegurar a permanência dos padrões estabelecidos e normatizar os corpos, impedindo, assim, que os sujeitos "desviados" vivessem sua sexualidade livremente (LOURO, 2004). Seja por ser considerada um crime ou patologia, o desejo direcionado a alguém do mesmo sexo foi constantemente repreendido e silenciado e, mesmo diante dos avanços obtidos, essas identidades continuam a serem silenciadas ainda hoje. Evidentemente, essas práticas não se relacionam apenas à sexualidade, mas, também, à expressão de gênero desses indivíduos de modo que, desde a infância, são traçadas fronteiras normativas que acabam por instituir o que é socialmente tido como naturalmente masculino ou feminino - como demonstra a narrativa de "Huerfanita" (TALAMENTES, 2011). Em suma, o que ocorre é que

aqueles e aquelas que transgridem as fronteiras do gênero ou de sexualidade, que atravessam ou que, de algum modo, embaralham e confundem os sinais considerados 'próprios' de cada um desses territórios são marcados como sujeitos diferentes e desviantes. Tal como atravessadores ilegais de territórios, como migrantes clandestinos que escapam do lugar onde deveriam permanecer, esses sujeitos são tratados como infratores e devem sofrer penalidades (LOURO, 2004, p. 87).

É natural, portanto, que ambos os contos apresentem personagens que exerçam essa função reguladora, sendo este outro elemento que aproxima essas narrativas. Em tal contexto, é interessante perceber que o papel regulador parte, de modo mais acentuado, do próprio núcleo familiar: em "Huerfanita" (TALAMENTES, 2011) este papel é reservado a Beto, pai de Pablo, enquanto em "On the line"

${ }^{7}$ Nossa tradução: "era sempre uma garota". 
(VÁSQUEZ, 2011) é a mãe de Emilio que cumpre essa função. Tal aspecto, é importante ressaltar, torna-se particularmente relevante aqui devido às interseccionalidades que constituem as identidades desses "seres de papel", o que nos leva à discussão de como alguns dos elementos que compõem a identidade $e$ cultura latina surgem como agentes em favor das práticas disciplinares que assegurem as normas de gênero.

Conforme já discutido na primeira parte desta pesquisa, uma das singularidades da literatura produzida por latinos nos Estados Unidos é a hibridez linguística dessas obras por meio do Spanglish e/ou codeswitching. Isso, é claro, não ocorre de maneira arbitrária, mas serve justamente como forma de legitimar uma identidade atravessada pela coexistência de diferentes línguas, bem como para refratar as constantes tensões que permeiam esse espaço heterogêneo (TORRES, 2001). É curioso, no entanto, como, em ambos os contos, essa hibridez linguística parece receber outra função: oprimir o sujeito queer.

Beto recorre constantemente à língua espanhola quando busca se referir ao filho de maneira pejorativa, especialmente no que se refere à masculinidade do garoto. Huerfanita, por exemplo, é o modo como ele passou a chamar Pablo após a morte de sua mãe biológica, termo que o estigmatiza pela ironia presente na escolha da flexão de gênero da palavra somada ao uso do diminutivo. Esse, então, torna-se um dispositivo de controle que busca desestabilizar o sujeito transgressor a fim de que este reveja suas práticas, estratégia que é utilizada por Beto de maneira recorrente: "iHuerfanita estúpida!" (TALAMENTES, 2011, p. 02) (TALAMENTES, 2011, p. 05) ${ }^{9}$; "I'm going to teach you how to be un hombre macho, not a pinche muchachita..." (TALAMENTES, 2011, p. 06) ${ }^{10}$.

Uma estratégia semelhante é utilizada em "On the line" (VÁSQUEZ, 2011), agora, pela mãe de Emilio, ao perceber que a relação entre o filho e Danny vai além da simples amizade. Aqui, todavia, a carga ideológica dos enunciados em questão configura-se, principalmente, por meio da palavra de autoridade: "No quiero a Danny in this house [...] ¿Me oístes?" (p. 13-14); "Porque yo mando aqui”" (p. 14) ${ }^{12}$;

\footnotetext{
${ }^{8}$ Nossa tradução: "Orfãzinha estúpida".

${ }^{9}$ Nossa tradução: "Não é meu filho".

${ }^{10}$ Nossa tradução: "Vou te ensinar como ser um hombre macho (um homem macho), não uma pinche muchachita (pobre garotinha).

${ }^{11}$ Nossa tradução: "No quiero (não quero) Danny nesta casa. [...] ¿Me oístes? (me ouviste?)".

12 Nossa tradução: "Porque eu mando aqui".
} 
“¡Suciera del diablo!” (p. 14) ${ }^{13}$. Sobre este último aspecto, é necessário mencionar a discussão realizada por Fiorin (2008) que, retomando Bakhtin, esclarece que todo enunciador, ao constituir seu discurso, sempre se utiliza do discurso de outrem, posto que "todo discurso é inevitavelmente ocupado, atravessado, pelo discurso alheio" (FIORIN, 2008, p. 19). Desse modo, a partir da associação da prática homoerótica ao "diablo", a mãe de Emilio reverbera o discurso religioso que classifica o ato sexual entre pessoas do mesmo sexo como pecaminoso, passível de punição. É relevante a menção, ainda, de que a voz do discurso religioso é classificada como uma voz de autoridade, sendo sua adesão incondicional; age, portanto, como uma força centrípeta, centralizadora, resistente a impregnar-se com outras vozes (FIORIN, 2008). Assim, mesmo que nos demais excertos apresentados o discurso religioso não surja de maneira explicita, é possível supor que o autoritarismo ali presente esteja, também, contaminado por ele.

Os aspectos analisados até o momento, portanto, evidenciaram os elementos análogos entre ambas as narrativas, a saber: a construção de personagens queer e latinos - que rompem com a ordem socialmente estabelecida, responsável por instituir uma sequência lógica e binária entre sexo-gênero-sexualidade; e, por outro lado, personagens que agem no sentido de reestabelecer essa lógica por meio de elementos que constituem a cultura latina, dentre os quais foi possível destacar, de maneira mais específica, o fator linguístico. É oportuno, agora, observar alguns elementos particulares de cada conto.

Ambas as personagens evidenciadas nas análises, Pablo e Emilio, têm consciência de sua condição queer e se reconhecem como tal sem maiores conflitos. Emilio, todavia, nunca chega a exteriorizar verbalmente o desejo que nutre pelo amigo e, quando confrontado pela mãe, recua ante a figura de autoridade materna. Quando, finalmente, tenta se impor, a opressão social faz com que Danny negue seu desejo e se afaste definitivamente de Emilio. O desfecho, portanto, refrata a dupla dificuldade enfrentada por sujeitos queer. a de autoafirmar sua condição - representada em Danny - e a dificuldade em se afirmar socialmente enquanto tal - personificada em Emilio.

Em "Huerfanita" (TALAMENTES, 2011), por outro lado, esconder-se na intenção de se proteger da opressão social não é uma opção, uma vez que a

${ }^{13}$ Nossa tradução: "Imundice do diabo!". 
temática do conto se volta à expressão de gênero, de modo que qualquer tentativa de ocultar esse elemento ocorreria de maneira muito mais complexa e delicada. É significativo, portanto que o desfecho do conto aponte uma direção que indica a possibilidade de libertação do sujeito queer, quando, em um acidente, Beto é esmagado por um carro enquanto Pablo serve de testemunha: "Beto's legs were as still and stiff as those of the Wicked Witch of the East under Dorothy's house. Life would be better. He waited another minute, just to be sure, and yelled out, 'Senaida!'” (TALAMENTES, 2011, p. 08) ${ }^{14}$.

Beto, naturalmente, personifica toda a opressão social que o sujeito queer enfrenta pelo simples fato de existir. Mesmo que não seja possível, nesse caso, falar de maneira específica sobre a sexualidade, não é possível ignorar como as práticas discursivas de Beto fazem com que os aspectos referentes à expressão de gênero de seu filho se tornem definidores de gênero e sexualidade, e, consequentemente, convertam-se em definidores de sujeito (LOURO, 2004). Assim, por meio desse desfecho, essa opressão, ao menos no ambiente familiar no qual Pablo está inserido, tem seu fim. Ele, como é possível perceber no excerto, tem consciência da liberdade que a morte de Beto ocasionará; sabe, então, que a partir daquele momento a vida será melhor. E, apenas para ter certeza de um destino melhor, hesita antes de chamar por socorro. Pablo, portanto, não apenas aceita e abraça sua condição queer, mas se mostra disposto a lutar pelo seu direito de expressão, pelo seu direito de ser.

Nesse bojo, é necessário mencionar, também, a caracterização do espaço como outra característica que singulariza "Huerfanita" (TALAMENTES, 2011). Toda a ação do conto ocorre em Juárez, cidade fronteiriça localizada no México. O território latino-americano, dessa maneira, configura-se como um ambiente hostil, potencializando o clima opressivo que permeia o conto. Foi em Juárez, por exemplo, que Filomena, mãe biológica de Pablo, desaparecera, sendo reencontrada sem vida no deserto e com o rosto desfigurado após algumas semanas, cenário que se mostra corriqueiro naquele meio ["Pretty young ladies often vanished in Juárez"

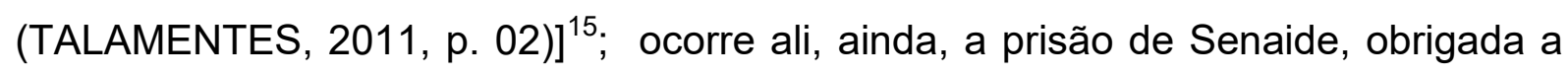
morar com Beto após o desaparecimento de Filomena, sendo ela, também,

\footnotetext{
${ }^{14}$ Nossa tradução: "As pernas de Beto estavam rígidas e imóveis como as da Bruxa Malvada do Leste, esmagadas pela casa de Dorothy. A vida, agora, seria melhor. Ele aguardou outro minuto, apenas para ter certeza, e gritou, 'Senaida!".

${ }^{15}$ Nossa tradução: "Belas moças desapareciam com frequência em Juárez".
} 
constantemente oprimida ["her place in his home is not one of voice or opinion - just work and occasional sex (TALAMENTES, 2011, p. 3) ${ }^{16}$; e, é claro, é da cultura daquele território que advêm muitas das práticas disciplinares em favor das normas de gênero, como foi possível perceber a partir das análises aqui realizadas.

\section{Considerações Finais}

Este artigo teve como objetivo analisar, por meio de uma perspectiva comparativista, de que maneira se dá a construção das personagens queer nos contos "Huerfanita" (TALAMENTES, 2011) e "On the line" (VÁSQUEZ, 2011) e de que modo a inteseccionalidade étnica que compõe a identidade desses sujeitos, a saber, a ascendência latino-americana, afeta suas vivências enquanto sujeitos queer.

Para isso, inicialmente, foram apresentados elementos que compõem as identidades e a literaturas latinas produzida nos Estados Unidos. Em seguida, foram introduzidos alguns elementos relacionados aos estudos queer para que, a partir disso, fosse possível discutir de que maneira estes se relacionam à identidade étnica latina. Não obstante o fato de que os sujeitos queer (e latinos) de interesse desse estudo são constituídos em narrativas ficcionais, foram abordadas questões em torno da personagem de ficção a partir do paradoxo gerado ante a hipótese de a ficção ser (CÂNDIDO, 2009), percebendo, também, como esses seres ficcionais se constituem como sujeitos essencialmente sociais e historicamente concretos, de modo que suas vozes se constroem como posições axiológicas em relação ao mundo (BAKHTIN, 2015).

Assim, após esse percurso, é possível responder à problemática de pesquisa levantada afirmando que a construção das personagens queer em ambos os contos se dá de maneira análoga no que se refere à autopercepção destes enquanto sujeitos queer. Isso, no entanto, não torna suas vivências mais simples. Ao viver sua condição queer - seja em sua expressão de gênero, como Pablo, ou em sua sexualidade, como Emilio - essas personagens acionam uma série de dispositivos sociais que agem no sentido de reestabelecer a ordem normativa que supõe e institui uma sequência natural em torno de uma lógica binária no que se refere à

\footnotetext{
${ }^{16}$ Nossa Tradução: "ela não ocupava, nesta casa, uma posição em que fosse possível ter voz ou opinião - servia apenas para trabalhar e sexo, ocasionalmente".
} 
caracterização de sexo-gênero-sexualidade, responsável por impor limites à concepção de gênero, tornando a heterossexualidade o destino inexorável dos sujeitos (LOURO, 2004).

Nesse contexto, é curioso perceber como o núcleo familiar é apresentado como o principal agente em favor dessa normatização. Isso, é claro, está ligado ao fato de que a tarefa de socialização primária dos sujeitos é realizada pela família (e outros níveis de socialização e introjeção de normas de comportamento social serão realizados em outras esferas, como as escolas e as instituições religiosas, por exemplo). Neste sentido, é esperado que os núcleos familiares transmitam e perpetuem concepções convencionais de comportamento (como a heterossexualidade). Não podemos ignorar aqui, ainda, como são utilizados, nesse processo, componentes da cultura latina, dentre os quais foi possível destacar, de maneira mais específica, o fator linguístico e geográfico - este último, conforme já explicitado, percebido apenas em "Huerfanita" (TALAMENTES, 2011). Há, portanto, em ambos os contos, a refração dos discursos que categorizam as identidades latinas e a condição queer como dicotômicas (DIAZ, 1998; FIELDS, 2009).

Dessa maneira, "Huerfanita" (TALAMENTES, 2011) e "On the line" (VÁSQUEZ, 2011) se constituem por meio do heterodiscurso das vozes sociais reais organizadas artisticamente por seus autores. Assim, foi possível constatar, por meio das análises realizadas, o confronto entre os diferentes discursos que cercam identidades complexas e fragmentadas, revelando um verdadeiro "jogo das identidades" (HALL, 2011) que culmina na marginalização de sujeitos, em função de sua expressão de gênero e/ou sexualidade, que já se encontram às margens por questões étnicas e culturais.

\section{Referências}

BAKHTIN, M. Teoria do romance I: a estilística. Tradução, prefácio, notas e glossário de Paulo Bezerra. São Paulo: Editora 34, 2015.

BRAIT, B. A personagem. São Paulo: Ática, 1985.

CANDIDO, A.; GOMES, P. E. S.; PRADO, D. A.; ROSENFELD, A. A Personagem de Ficção. São Paulo: Perspectiva, 2009.

CÓRDOBA, D.; SÁEZ, J.; VIDARTE, P. TeoríaQueer: Políticas Bolleras, Maricas, Trans, Mestizas. 2.ed. Barcelona y Madrid: Editorial Egales, 2007. 
FERNANDES, C. E. A. Configurações do desejo homoerótico na contística brasileira do século XX. 2012. 201 f. Dissertação (Mestrado em Literatura e Interculturalidade) - Programa de Pós-Graduação em Literatura e Interculturalidade, Universidade Estadual da Paraíba, Campina Grande, 2012.

FIORIN, José L. Introdução ao pensamento de Bakhtin. São Paulo: Ática, 2008.

HALL, S. A identidade cultural na pós-modernidade. Trad. Tomaz Tadeu da Silva, Guacira Lopez Louro. 11. ed.Rio de Janeiro: DP\&A, 2006.

LÓPEZ, A. Nuevas instancias transculturales de la literatura latinoamericana: la tradición latina de los Estados Unidos. Amerika [En ligne], 13, 2015. Disponível em $<$ https://amerika.revues.org/6918\#tocfrom1n1>.

Ni di aqui ni de allá: la articulación entre poesía niuyorriqueña y tradición latinoamericana en la obra de Miguel Algarín y Tato Laviera. Caracol, n. 8, p. 130156, jul-dez, 2014.

LOURO, G. L. Marcas do corpo, marcas de poder. In: Um corpo estranho: ensaios sobre a sexualidade e teoria queer. Belo Horizonte: Autêntica, 2004, p. 75- 90.

Foucault e os estudos queer. In: RAGO, M; VEIGA-NETO, A. (Orgs.). Para uma vida não fascista. Belo Horizonte: Editora Autêntica, 2009, p. 135-142.

MACHADO, A. M.; PAGEAUX, D. Da literatura comparada à teoria da literatura. Lisboa: Edições 70, 1998.

RICE-GONZÁLEZ, C.; VÁZQUEZ, C. From macho to mariposa: new gay latino fiction. United States: Tincture, 2011.

TALAMENTES, D. A. Huerfanita. In: RICE-GONZÁLEZ, C.; VÁZQUEZ, C. From macho to mariposa: new gay latino fiction. United States: Tincture, 2011, p. 01-08.

TORRES, S. Nosotros in USA: literatura, etnografia e geografias de resistência. Rio de Janeiro: Jorge Zahar Ed., 2001, p. 09-15.

VÁSQUEZ, B. On the line. In: RICE-GONZÁLEZ, C.; VÁZQUEZ, C. From macho to mariposa: new gay latino fiction. United States: Tincture, 2011, p. 08- 16. 